\title{
Reply to comment by Alley et al. on "Catastrophic ice shelf breakup as the source of Heinrich event icebergs"
}

\author{
Christina L. Hulbe \\ Department of Geology, Portland State University, Portland, Oregon, USA
}

Received 22 November 2004; revised 30 November 2004; accepted 1 December 2004; published 15 February 2005.

Citation: Hulbe, C. L. (2005), Reply to comment by Alley et al. on "Catastrophic ice shelf breakup as the source of Heinrich event icebergs," Paleoceanography, 20, PA1011, doi:10.1029/2004PA001118.

[1] The authors of Hulbe et al. [2004] are grateful for the opportunity afforded by Alley et al.'s [2005] remarks. The original draft of the comment was shared via e-mail, after which a compelling dialog ensued among the combined group of authors. This is, we believe, exactly what should transpire in the scientific marketplace of ideas, and we were pleased to be approached by Alley et al. [2005] in this way.

[2] Three glaciologic issues do seem to warrant clarification. First, the notion of ice shelves as debris filters derives mainly from observations at the fronts of Antarctica's large ice shelves, not from the small fringing ice shelves advocated in the work of Hulbe et al. [2004]. Indeed, the presence of significant englacial debris in the shattered remains of the Larsen B ice shelf was a primary motivation in our revisitation of the original ice shelf hypothesis. Second, it has been observed recently that glaciers in the Antarctic Peninsula and elsewhere are speeding up in the wake of ice-shelf disintegration. The details of those speed-ups require investigation, but this may be a source for additional Heinrich layer sediment after the initial ice-shelf breakup pulse. Third, the "trigger" for ice-shelf breakup is summertime warmth, a signal that may not be apparent in the mean annual temperature revealed by ice-core isotopes.

[3] Through all the discussion, one fact seems clear: neither an ice-shelf nor an ice-stream surge model adequately addresses all the known demands of the Heinrich layer record. Neither mechanism is completely unique in its sedimentary and geomorphic signature, yet hope exists, for each has particular attributes that might be exploited in identifying the correct mechanism.

[4] We believe our original paper addressed the concerns raised by Alley et al. [2005]. Thus we decline further comment and eagerly await more news from the geologic record. Our goal is to improve the understanding of Heinrich events, not to cling to one explanation or another.

\section{References}

Alley, R. B., J. T. Andrews, D. C. Barber, and P. U. Clark (2005), Comment on "Catastrophic ice shelf breakup as the source of Heinrich event icebergs" by C. L. Hulbe et al., Paleoceanography, PA1009 doi:10.1029/2004PA001086.
Hulbe, C. L., D. R. MacAyeal, G. H. Denton, J. Kleman, and T. V. Lowell (2004), Catastrophic ice shelf breakup as the source of Heinrich event icebergs, Paleoceanography, 19, PA1004, doi:10.1029/2003PA000890.
C. L. Hulbe, Department of Geology, Portland State University, Portland, OR 97207, USA. (chulbe@pdf.edu) 